\title{
Phonological and semantic priming: Evidence for task-independent effects
}

\author{
AÏCHA ROUIBAH and GUY TIBERGHIEN \\ Institut des Sciences Cognitives, Lyon, France \\ and \\ STEPHEN J. LUPKER \\ University of Western Ontario, London, Ontario, Canada
}

\begin{abstract}
The questions asked in the present experiments concern the generality of semantic and phonological priming effects: Do these effects arise automatically regardless of target task, or are these effects restricted to target tasks that specifically require the retrieval of the primed information? In Experiment 1 , subjects produced faster color matching times on targets preceded by a masked rhyming prime than on targets preceded by an orthographic control or an unrelated prime. This result suggests that automatic priming effects on the basis of phonological similarity can be obtained even when the target task does not make use of phonological information. This claim was reinforced in Experiment 2 in which a rhyme priming effect and a semantic priming effect were found in a semantic categorization task. In Experiment 3, the target task was phonological (rhyme detection), and, again, both phonological and semantic priming effects were observed. Finally, in Experiments 4 and 5, in a replication and an extension of Experiment 1, phonological and semantic priming effects were found in a color matching task, a task involving neither phonological nor semantic processing. These results are most straightforwardly interpreted by assuming that both semantic and phonological priming effects are, at least in part, due to automatic activation of memorial representations.
\end{abstract}

Although there is a large amount of literature on semantic priming, there have been relatively few studies concerned with phonological priming. However, a number of models of the mental lexicon clearly do predict that priming based on phonological similarity should be obtained. In Collins and Loftus's (1975) model, for example, a lexical network containing concepts' names is assumed to be organized on the basis of phonological similarity. When a word is processed, activation spreads from its lexical unit to lexical units for words that are phonologically similar, priming those units. In Forster's (1976) model, a structure containing words' phonological representations is assumed to be organized on the basis of phonological similarity. As will be discussed, Hillinger (1980) suggested that this model will also predict a phonological priming effect if the assumption is made that, when a word is processed, there is a spread of activation among entries within this phonological file.

One of the first attempts to investigate phonological priming was reported by Meyer, Schvaneveldt, and Ruddy (1974). In their experiments, subjects had to decide

This research was supported by Conseil de la Région Rhône-Alpes Grant HI 09130000 to G.T. and by a Conseil de la Région Rhône-Alpes grant to A.R. to allow her to hold a postdoctoral position at the University of Western Ontario. The authors thank Guy Denhière and François Rastier for their helpful comments on earlier drafts of this paper. Correspondence should be addressed to A. Rouibah, Institut des Sciences Cognitives, CNRS UPR 9075, 67 boulevard Pinel, 69675 Bron cedex, France (e-mail: rouibah@isc.cnrs.fr). whether two simultaneously presented letter strings were words. Meyer et al. reported a nonsignificant facilitory effect when the word pairs were graphemically similar and rhyming (e.g., HATE-MATE) and a significant inhibitory effect when the word pairs were graphemically similar but nonrhyming (e.g., COUCH-TOUCH). In general, these results seem to provide at least some support for the existence of phonological priming.

In a follow-up to Meyer et al. (1974), Hillinger (1980) showed much clearer phonological priming effects. In particular, Hillinger demonstrated that both visual and auditory prime presentations facilitate visual lexical decisions even when the rhyming words are not graphemically similar (e.g., EIGHT-MATE). In his discussion, Hillinger also raised the issue of the similarity, between semantic priming effects and the phonological priming effects he had obtained. Often, semantic priming facilitation was assumed to be the result of a passive spreading activation between related lexical entries; however, he felt that "this process cannot be directly applied to rhyming facilitation without modifying some current assumptions about the structure of lexical memory" (Hillinger, 1980 , p. 121). In particular, Hillinger suggested that his results would be best thought of in terms of Forster's (1976) model and suggested that rhyme priming comes from a spread of activation within the phonological file.

Hillinger's (1990) analysis appears to raise four questions: (1) Under what circumstances does one obtain priming effects based on phonological similarity? (2) Could such effects be attributed to an automatic process? (3) Are 
the processes involved in phonological priming based on the activation of lexical (or other memorial) representations? (4) How extensive is the parallel between semantic and phonological priming effects? As will be discussed, although some research effort has been directed at trying to answer the first three of these questions, up to this point, somewhat less attention has been paid to the fourth.

Martin and Jensen (1988) and Peter, Lukatela, and Turvey (1990) failed to replicate Hillinger's (1980) rhyme priming effects using more standard prime-target presentations. Thus, they argued that the effects obtained by Hillinger were caused by subjects' strategies. Indeed, in Hillinger's experiments, subjects did have to make a lexical decision about the prime. Thus, subjects undoubtedly realized that there was a large number of rhyming word pairs and, as well, that they would have sufficient time between prime and target presentations to exploit that fact. As a result, subjects may have engaged in some sort of phonologically based strategy, which could have been responsible for the facilitation effects. Presumably, the best way to make certain that subjects do not invoke strategies and that any effects one does observe are automatic would be to mask the prime to prevent its conscious identification (Holender, 1986; Marcel, 1983).

Humphreys, Evett, and Taylor (1982) were one of the first sets of investigators to examine the question of automatic phonological processing using masked primes. They presented mask-prime-target-mask sequences to subjects who had to write down all the words they could recognize. Results indicated that target report was higher when targets were preceded by homophone primes (e.g., MAID-MADE) than when targets were preceded by orthographic control primes (e.g., MARK-MADE). Such a phonological priming effect did not appear with pseudohomophone primes, but it was observed for both regular and irregular targets. The authors concluded that automatic phonological priming does occur and is based only on interactions among lexical units.

In contrast, Perfetti, Bell, and Delaney (1988) observed a phonological priming effect from pseudohomophone primes in a task similar to the one used by Humphreys et al. Furthermore, Lukatela and Turvey (1990a, 1990b) obtained phonological priming effects with pseudoword - word and word-pseudoword prime-target pairs in Serbo-Croatian, and Lukatela, Carello, and Turvey (1990) found similar effects with word-word and pseudowordpseudoword prime-target pairs. Thus, while these results argue against Humphreys et al.'s (1982) conclusion that phonological priming effects are entirely lexically based, they support Humphreys et al.'s other conclusion that phonological priming occurs and is a result of automatic processes.

Perfetti and Bell's (1991) results suggest that one could explain the difference between Humphreys et al.'s (1982) and Perfetti et al.'s (1988) data in terms of different prime presentation times. With pseudoword primes, presented for $35 \mathrm{msec}$, Perfetti and Bell observed an orthographic priming effect but not a phonological priming effect. These data are similar to those obtained by Humphreys et al. (1982). However, when the same pseudoword primes were presented for $65 \mathrm{msec}$, both an orthographic priming effect and a phonological priming effect appeared-results that are more consistent with those reported by Perfetti et al. These data yield some new information about the time course of phonological processing. That is, one appears to need a prime presentation time/ stimulus onset asynchrony (SOA), of at least $60 \mathrm{msec}$ before sufficient phonological information is available to produce a phonological priming effect. Ferrand and Grainger's (1992) results substantiate this conclusion.

Taken together, the data reported above indicate that the prime's phonology can influence at least certain word recognition processes automatically - that is, without invoking a conscious strategy-although these effects do not arise immediately upon prime presentation. At this point, however, the data do not clearly implicate a mechanism by which the effects occur; in particular, it is unclear what role lexical representations and lexically based processing might play in producing these effects.

We turn next to the final issue, the nature of the relationship between semantic and phonological processing. In recent years, the associative-priming-mediated-byphonology paradigm has been used to test the hypothesis that phonological processing activates associative information, which then heightens the activation levels of lexical representations. For example, Fleming (1993) tested the hypothesis that associative priming mediated by homophones can be observed (e.g., DOUGH-DEER). Although Fleming obtained direct associative priming effects, he did not obtain any priming effects with homophone primes in his first two experiments. In contrast, however, Lukatela and Turvey (1993) obtained both direct and phonologically mediated associative priming effects using both homophones and pseudohomophones as primes. Their results suggest that automatic associative priming can be mediated by phonology.

In an extension of these results, Lesch and Pollatsek (1993) reported that, with a brief prime exposure time $(50 \mathrm{msec})$, the homophone of a word associated with a target facilitated target pronunciation as much as the associated word itself. This facilitation did not appear with a longer prime exposure time $(200 \mathrm{msec})$ (see also Lukatela \& Turvey, 1994). The idea is that, with a long prime presentation time $(200 \mathrm{msec})$, there is time for an orthographic verification process, which should inhibit phonological processing for targets related to the homophone of the prime. Lesch and Pollatsek further argued that the facilitation effects they observed were the result of prelexical phonological processing leading to heightened lexical activation. They concluded: "The data thus provide support for a model of word recognition in which meaning is rapidly and automatically accessed through a phonological code" (Lesch \& Pollatsek, 1993, p. 291).

A related series of associative priming experiments was reported by Frost and Bentin (1992) using both homophonic and heterophonic Hebrew homographs as primes 
followed by a target word related to one of the prime's possible meanings. With an SOA of $100 \mathrm{msec}$, homophonic homograph primes led to associative priming effects when the target was related to either the more frequent or the less frequent member of the homograph pair, whereas heterophonic homograph primes led to priming effects only when the target was related to the more frequent member of the pair. Frost and Bentin argued that if meaning were retrieved solely on the basis of orthography, heterophonic and homophonic homographs should have produced the same pattern of priming. Thus, they suggested that phonological representations are the means by which meaning is accessed and, hence, priming is produced. This interpretation is compatible with Lesch and Pollatsek's (1993) and Lukatela and Turvey's (1994) conclusions. Together, these studies provide strong support for the conclusion that prelexical phonological processing occurs automatically, producing heightened lexical activation that supports lexically based priming.

\section{EXPERIMENT 1}

The aim of Experiment 1 was to determine whether priming effects can be obtained on the basis of phonological similarity in a slightly different situation. As argued, previous results seem to suggest that prelexical phonological processing is automatic, leading to heightened activation in lexical units sharing the prime's phonology. As such, a rhyme priming effect should generally be observed with a prime-mask-blank-target procedure, with a brief exposure of the prime and a short SOA in such tasks as naming or lexical decision. The question here is whether the same is true in a task for which phonological processing of the target is completely irrelevant-in particular, a color matching task. In this task, subjects were presented with a color patch prior to each trial, and the target was also presented in color. The subject had to decide whether those two colors were identical. The expectation was that the rhyming prime should facilitate lexical processing of the target. Our working hypothesis was that the more rapid completion of lexical processing would then allow subjects to begin and, hence, complete the process of making a color matching decision more rapidly as well.

It should be noted that previous research using a similar paradigm (Tanenhaus, Flanigan, \& Seidenberg, 1980 ) has demonstrated inhibitory effects from phonologically similar primes in a color naming task. The present task differed from those experiments in an important way: The target task was color matching rather than color naming, and, thus, any consciously available phonological code from the target would not be expected to interfere with the buttonpress responses required in this task.

A final consideration in designing this experiment was to create conditions that would allow a better way of teasing apart phonological priming effects and orthographic priming effects. Generally, when rhyming word pairs are used to show phonological effects, the primes and targets are also orthographically similar. It is then difficult to know whether the obtained effects are due to phonological or orthographic similarity. In fact, even when primes orthographically similar but phonologically dissimilar to targets are used, in an attempt to evaluate the influence of orthographic similarity, there is, inevitably, noticeable phonological similarity between these primes and their targets. One way in which we tried to address this problem was to present disyllabic prime and target words where the phonological similarity was somewhat less substantial-in particular, it was only in the second syllable ${ }^{1}$ (e.g., buvard/lézard). This also served to decrease the orthographic similarity of the rhyming pairs. More important, however, we controlled orthographic similarity by measuring it and creating an orthographic control condition in which primes and targets had as much orthographic similarity as in the phonological priming condition but had essentially the same level of phonological similarity as control pairs. To accomplish this, orthographic similarity (OS) was estimated using Van Orden's $(1984,1987)$ formula (see Appendix A). ${ }^{2}$

In the end, then, there were three conditions: (1) a rhyming condition (e.g., buvard/lézard), (2) an orthographic control condition (e.g., larron/lézard), and (3) an unrelated control condition (e.g., hublot/lézard). Any difference between the orthographic control and unrelated control conditions should be attributed to orthographic priming. Note also that the difference between the rhyming and unrelated control conditions should be at least as large as that between the orthographic control condition and the unrelated control condition, since the rhyming pairs have the same OS values as the orthographic control pairs. Most importantly, if a difference is observed between the rhyming pairs and the orthographic control pairs, it is most likely truly due to phonological similarity.

\section{Method}

Subjects. Sixty undergraduate students from the University of Grenoble, all native French speakers, participated in the experiment for course credit.

Stimuli. The targets were 60 words: 30 were used as "yes" targets, and 30 were used as "no" targets. Each "yes" target was matched with a "no" target that was similar in syllable length and frequency ("yes" targets' frequency $=758$; "no" targets' frequency $=692$; according to Content, Mousty, and Radeau's, 1990, lexical frequency database for written French words, which was used to select stimuli in all the other experiments in this paper as well). All the targets were written in one of five possible colors (red, blue, green, pink, or yellow). When a "yes" target was presented in one of these colors, its corresponding "no" target was presented following the same color patch but the word itself was in a different color.

For each of these 30 pairs of target words, 3 different prime words were selected (see Appendix B), each one sharing a different relationship with the "yes" member of the target pair (on the basis of their orthographic and phonological similarity to the "yes" target). The nature of these similarities defined the three experimental conditions: (1) prime and "yes" target were phonologically similar (i.e., they rhymed; e.g., buvard/lezard) and were orthographically similar (mean OS $=42 \% ; S D=14$ ), (2) prime and "yes" target were phonologically dissimilar and orthographically similar (e.g., larron/ 
lézard; mean OS $=45 \%, S D=11$ ), and (3) prime and "yes" target were neither phonologically nor orthographically similar (e.g., hublot/ lézard; mean OS $=12 \%, S D=8$ ). All the primes were frequent (mean $=741$ ), and the three primes assigned to a given "yes" target were equivalent in length.

Three lists of 60 trials were created by combining primes and targets. The stimuli for a trial consisted of a color, a prime, a mask, and a target. All 60 targets were presented to each subject. For the three lists, (1) 10 "yes" targets were preceded by a rhyming prime, (2) 10 "yes" targets were preceded by an orthographic control prime and (3) 10 "yes" targets were preceded by an unrelated control prime, for a total of 30 "yes" targets. The 10 "yes" targets preceded by rhyming primes in one list were preceded by orthographic control primes in a second list and by unrelated control primes in a third list. In addition to the 30 prime/"yes" target pairs, 30 prime/"no" target pairs were presented. The 30 "no" targets were preceded by unused primes from the rhyming, orthographic control, or unrelated conditions, but, in fact, there was no relation between these primes and the "no" targets with which they were paired. The 60 trials of each list were presented in a different random order to each subject with the constraints that the subject did not see more than three "yes" (or "no") targets in a row or more than two primes from the same condition in a row.

Procedure. The subjects sat in front of the screen of a Macintosh Quadra 700 computer. ${ }^{3}$ A colored square $(2.5 \times 2.5 \mathrm{~cm})$ was presented in the center of the screen for $1,498 \mathrm{msec}$, after which the screen remained blank for $196 \mathrm{msec}$. A prime was then presented in the center of the screen for $49 \mathrm{msec}$, followed by the mask (nine uppercase Xs: XXXXXXXXX) for $49 \mathrm{msec}$. Finally, after an interstimulus interval, containing a blank screen, of $49 \mathrm{msec}$, the colored target was presented and stayed on the screen until the subject responded. Primes were presented in uppercase letters, and targets were presented in lowercase letters.

The subjects had to decide whether targets were written in the same color as the square they had been presented with at the start of the trial. The subjects were asked to make this decision as fast and as accurately as possible. They gave their responses by pressing a designated key on the computer keyboard with the dominant hand when the response was "yes" and a different designated key with the other hand when the response was "no."

\section{Results}

Although the intention was to analyze both response times (RTs) and error rates to "yes" targets, the subjects made virtually no errors to "yes" targets, preventing any meaningful analysis of error rates. RTs to correct "yes" targets were analyzed using analyses of variance (ANOVAs) in which both subjects and items were separately treated as random factors.

A significant effect of experimental condition was observed by subjects $\left[F(2,118)=134.311, M S_{\mathrm{e}}=30,078\right.$, $p<.01]$ and by items $\left[F(2,87)=31.392, M S_{\mathrm{e}}=15,156\right.$, $p<.01]$. This effect was due to the fact that the match of "yes" targets" color was faster when primes and "yes" targets rhymed $(433 \mathrm{msec})$ than when primes and "yes" targets were either unrelated $(474 \mathrm{msec})$ [by subjects, $F(1,118)=222.992, M S_{\mathrm{e}}=223.95, p<.01$; by items, $\left.F(1,87)=52.224, M S_{\mathrm{e}}=482.821, p<.01\right]$ or only orthographically related $(469 \mathrm{msec})$ [by subjects, $F(1,118)=$ $177.327, M S_{\mathrm{e}}=223.95, p<.01$; by items, $F(1,87)=$ $\left.41.314, M S_{\mathrm{e}}=482.821, p<.01\right]$. On the other hand, the difference between the orthographic control condition and the unrelated condition was not significant (see Table 1).
Table 1

Mean RTs (in Milliseconds), Priming Effects (in Milliseconds), and Percent Errors Obtained in the Color Matching Task for the Phonological, Orthographic, and Control Conditions

\begin{tabular}{lccc}
\hline Prime-Target Relation & RT & Priming Effect & \% Error \\
\hline $\begin{array}{c}\text { They rhyme and have a } \\
\text { high OS rate }\end{array}$ & 433 & $41^{*}$ & 0.6 \\
$\begin{array}{c}\text { They do not rhyme but } \\
\text { have a high OS rate }\end{array}$ & 469 & 5 & 0.7 \\
$\begin{array}{c}\text { They do not rhyme and } \\
\text { have a small OS rate }\end{array}$ & 474 & & 0.6 \\
\hline
\end{tabular}

*Significant difference both by subjects and by items.

\section{Discussion}

The first point to note is that there was only a very small, and nonsignificant, orthographic priming effect. Thus, apparently, an OS rate of about $42 \%$ between primes and targets did not facilitate target processing in this task when the prime was presented for $49 \mathrm{msec}$ and the SOA was $147 \mathrm{msec}$. More importantly, on the basis of the fact that there was no orthographic priming effect, the facilitation effect obtained when primes and targets were phonologically and orthographically similar appears to be a completely phonological priming effect. Thus, this new phonological facilitation effect, obtained with French stimuli, with a strong control on orthographic similarity, and with a slightly different type of phonological relationship (rhyming final syllables), provides additional support for the reality of phonological priming effects.

In addition, the conditions under which this effect was obtained clearly indicate that it is dependent on a rapidly activated phonological code. Indeed, the brief exposure of the primes and the use of a mask immediately after prime presentation are conditions under which it can be assumed that only the more rapidly activated codes can influence target processing. Finally, the fact that phonological facilitation was obtained with a task that did not require phonological processing seems to indicate that this effect is based on an obligatory process.

On the basis of the long history of color-word interference experiments following Stroop's (1935) initial report, what might seem a bit unusual was that the effect of a phonological relationship on target processing was facilitory rather than inhibitory-that is, that phonological similarity aided rather than delayed responding to the target. The crucial difference here, however, is that with a naming task one creates a situation in which there is a competition between two phonological codes, the one of the word and the one of the color, whereas in a color matching task, such as the one used here, there is no reason for such competition to take place. As a result, any benefits of priming the target word can more easily be seen.

The data of Experiment 1, then, show that priming effects based on phonological similarity can be obtained even when the task itself does not require the retrieval of phonological information. In the next experiments, we attempted to understand what types of codes are being ac- 
tivated as a result of prime processing and how that process works.

It is certainly possible that semantic and phonological processes interact during word recognition, a point most strongly supported by data showing that associative priming can be mediated by phonology (Frost \& Bentin, 1992; Lesch \& Pollatsek, 1993; Lukatela \& Turvey, 1991, 1993, 1994). Thus, one could certainly argue that phonological priming may also aid semantic processing. In Experiments 2 and 3 , we addressed the question of how phonological and semantic processes may interact.

In Experiment 2, we an attempted to show phonological priming in a semantic categorization task - that is, a task requiring access to semantic representations. The hypothesis is that phonological similarity will lead to activation of processing structures (possibly lexical structures) that will aid semantic processing. In Experiment 3, the question was turned around. That is, the question was whether semantically related primes activate structures that aid phonological processing. If so, semantic priming effects should be observed in a phonological task (a rhyme detection task). Experiments 2 and 3, therefore, were attempts to test the general idea that the type of activation created by our masked primes is a generic activation of interrelated structures. If this hypothesis is accurate, phonological and semantic priming effects would arise automatically, regardless of the target task.

Finally, in order to help understand how phonological processing might interact with semantic processing, we investigated the time course of the two processes. For example, if phonological and semantic processes are serially organized, one might expect a decrease in, or the disappearance of, the short SOA $(147-\mathrm{msec})$ phonological priming effect when the SOA gets longer $(399 \mathrm{msec})$. On the other hand, it would be unclear what to predict for how semantic priming effects would interact with SOA. Presumably, these effects would take some time to become firmly established, and, thus, they may not be full-blown at the short SOA.

\section{EXPERIMENT 2}

\section{Method}

Subjects. Eighty undergraduate students from the University of Grenoble, all native French speakers, participated in the experiment for course credit. None of these subjects had participated in Experiment 1 .

Stimuli. The same 60 targets ( 30 "yes" targets and 30 "no" targets) that were used in Experiment 1 were again used in this experiment. The "yes" targets all belonged to one of eight different semantic categories. For each of these 30 "yes" targets, there was a paired "no" target that did not belong to the same category. Thus, for a given semantic category, it was possible to present either a target belonging to this category ("yes" target) or a matching target belonging to another semantic category ("no" target).

For each of these 30 pairs of target words, four different prime words, defined in terms of whether or not they had a phonological relationship with the "yes" target and whether or not they had a semantic relationship with the "yes" target, were selected (see Appen$\operatorname{dix} \mathrm{C}$ ). Thus, there were four experimental conditions: (1) a related- rhyme condition, in which prime and target belonged to the same semantic category and rhyme (e.g., homard/lézard), (2) a relatednonrhyme condition, in which prime and target belonged to the same semantic category but did not rhyme (e.g., bélier/lézard), (3) an unrelated-rhyme condition, in which prime and target did not belong to the same semantic category but rhymed (e.g., buvard/ lézard), and (4) an unrelated-nonrhyme condition (the control condition), in which prime and target did not belong to the same semantic category and did not rhyme (e.g., hublot/lézard). All the primes were frequent words (mean frequency $=741$ ), and the $O S$ between primes and targets were controlled so that it was high for all the conditions except for the control condition, for which it was low (12\%). Because the OS rate is around $40 \%$ when two words rhyme, we decided to fix the OS rate to this value for all the experimental conditions; thus, if differences were obtained between conditions, they would not be attributable to orthographic relations (relatedrhyme condition OS $=45 \%$; related-nonrhyme condition $\mathrm{OS}=$ $32 \%$; unrelated-rhyme condition OS $=42 \%$ ).

Four lists of 60 trials were created. A trial consisted of a semantic category, a prime, a mask, and a target. All 60 targets were presented to each subject. For each condition, there were either 7 or 8 "yes" targets. For the four lists, 7 or 8 "yes" targets were preceded by a related-rhyme prime, 7 or 8 were preceded by a related-nonrhyme prime, 7 or 8 were preceded by an unrelated-rhyme prime, and 7 or 8 were preceded by an unrelated prime, for a total of 30 prime/"yes" target pairs. The 7 or 8 "yes" targets preceded by one kind of prime in one list were preceded by another kind in the other lists. In addition to the 30 prime/"yes" target pairs, 30 prime/"no" target pairs were presented. The primes for these pairs were again unused primes from the "yes" targets, and there was no relation between these primes and the "no" targets. The 60 trials of each list were presented randomly with the constraints that the subjects could not see more than three "yes" (or "no") targets in a row or more than two primes from the same condition in a row. The presentation order of the 60 targets was different for each subject.

Procedure. The experimental procedure was generally the same as that in Experiment 1. The main exceptions were that, at the beginning of each trial, the subjects saw the name of a semantic category instead of a colored square, that all the stimuli (category name, prime, mask, and target) were written in black, and that two different SOAs (147 and $399 \mathrm{msec}$ ) were used. The longer SOA was created by increasing the duration of the blank screen between mask and target to $301 \mathrm{msec}$. SOA was a between-subjects factor. The subjects' task was to decide whether targets belonged to the category they saw at the beginning of the trial. They made their responses in the same way as in Experiment 1, by pressing a key with the dominant hand for a "yes" response and a different key with the other hand for a "no" response.

\section{Results}

Both mean semantic decision times for "yes" targets and mean error rates for "yes" targets were analyzed. Two ANOVAs, one treating subjects as a random factor and one treating items as a random factor, were carried out for each dependent variable. In all ANOVAs, the factors were SOA (147 vs. $399 \mathrm{msec}$ ), phonological relatedness (rhyming vs. nonrhyming), and semantic relatedness (belonging vs. not belonging to the same category).

With respect to the SOA factor, responses latencies were shorter with an SOA of $399 \mathrm{msec}$ than with an SOA of $147 \mathrm{msec}$; however, this difference was significant only by items $\left[F(1,116)=41.29, M S_{\mathrm{e}}=83,701, p<.01\right]$ and not by subjects $\left[F(1,78)=3.557, M S_{\mathrm{e}}=112,200, p=\right.$ $.063]$. SOA did not interact with any of the other factors. 
A significant effect of semantic relatedness was obtained both by subjects $\left[F(1,78)=54.40, M S_{\mathrm{e}}=64,297\right.$, $p<.01]$ and by items $\left[F(1,116)=16.096, M S_{\mathrm{e}}=49,766\right.$, $p<.01]$. Semantic categorization of "yes" targets was $32 \mathrm{msec}$ faster when the prime and target belonged to the same category $(609 \mathrm{msec})$ than when the prime and target belonged to different categories $(641 \mathrm{msec})$ (see Table 2 ).

A significant effect of phonological relatedness was also obtained both by subjects $\left[F(1,78)=64.61, M S_{\mathrm{e}}=\right.$ $86,001, p<.01]$ and by items $\left[F(1,116)=20.35, M S_{\mathrm{e}}=\right.$ $62,920, p<.01]$. Semantic categorization of "yes" targets was $28 \mathrm{msec}$ faster when the prime and target rhymed $(611 \mathrm{msec})$ than when the prime and target did not rhyme (639 msec).

As the results in Table 2 also indicate, there was a tendency for the semantic and phonological priming effects to be slightly underadditive in that the priming effect in the semantically and phonologically related condition was smaller than the sum of the two overall priming effects. The interaction between semantic and phonological relatedness was, however, not significant [by subjects, $F(1,78)=2.07$; by items, $F(1,116)=0.875]$.

No effects were significant in the error analysis; however, the overall error rate was low $(2.8 \%)$.

\section{EXPERIMENT 3}

\section{Method}

Subjects. Eighty undergraduate students from the University of Grenoble, all native French speakers, participated in this experiment for course credit. None of these subjects had participated in Experiment 1 or Experiment 2

Stimuli. The 60 targets ( 30 "yes" targets and 30 "no" targets) and the 120 primes, which were related to the "yes" targets in the four different ways (related-rhyme, related-nonrhyme, unrelatedrhyme, and unrelated-nonrhyme), that were used in Experiment 2 were used to create prime-target pairs in a similar fashion in this experiment. Like in Experiment 2, four lists of 60 trials were constructed by combining primes and targets. However, because in this experiment the task was a rhyme decision, a trial now consisted of a rhyme ending, a prime, a mask, and a target. Rhyme endings that did match those of the target were paired with the 30 "yes" targets, whereas endings that did not rhyme with the targets were paired with the 30 "no" targets. The presentation order of these 60 trials followed the same constraints as in Experiment 2.

Procedure. The experimental procedure was the same as that in Experiment 2 except that the subjects heard a voice pronouncing a rhyme ending instead of seeing the name of a category on the screen. The subjects had to decide whether the target rhymed with the ending they had heard beforehand. They made their responses in the same way as in Experiment 2.

\section{Results}

As in Experiment 2, mean latencies for "yes" targets and mean error rates for "yes" targets were analyzed. Two ANOVAs, one treating subjects as a random factor and one treating items as a random factor, were carried out for each dependent variable.

As before, a main effect of SOA was observed: Latencies were shorter with the longer SOA. However, this difference was significant only by items $[F(1,116)=74.551$, $\left.M S_{\mathrm{e}}=91,377, p<.01\right]$ and not by subjects $[F(1,78)=$ $\left.3.233, M S_{\mathrm{e}}=119,970, p=.076\right]$. Also as before, there were no interactions between SOA and the other factors.

Semantic relatedness was significant both by subjects $\left[F(1,78)=185.29, M S_{\mathrm{e}}=61,938, p<.01\right]$ and by items $\left[F(1,116)=18.310, M S_{\mathrm{e}}=47,348, p<.01\right]$. That is, rhyme detection was $28 \mathrm{msec}$ faster when the prime and "yes" target belonged to the same category $(518 \mathrm{msec})$ than when the prime and "yes" target belonged to different categories $(546 \mathrm{msec})$. Phonological relatedness was also significant both by subjects $[F(1,78)=188.274$, $\left.M S_{\mathrm{e}}=81,344, p<.01\right]$ and by items $[F(1,116)=24.145$, $\left.M S_{\mathrm{e}}=62,436, p<.01\right]$. Rhyme detection was $32 \mathrm{msec}$ faster when the prime and "yes" target rhymed $(516 \mathrm{msec})$ than when the prime and "yes" target did not rhyme (548 msec).

As the results in Table 3 indicate, there was again an indication that the two priming effects were underadditive (i.e., the priming effect in the semantically and phonologically related condition was smaller than the sum of the two overall priming effects). Unlike in Experiment 2, however, the interaction of semantic and phonological relatedness was significant both by subjects $[F(1,78)=$ $\left.30.42, M S_{\mathrm{e}}=14,071, p<.01\right]$ and by items $[F(1,116=$ $\left.4.171, M S_{\mathrm{e}}=10,787, p<.05\right]$.

Further analysis of this interaction revealed that all three experimental conditions in which there was a relationship between prime and target were significantly different from the unrelated-nonrhyme condition: when the prime and target rhymed but belonged to different semantic categories [by subjects, $F(1,78)=176.31, M S_{\mathrm{e}}=$ $462.493, p<.01$; by items, $F(1,116)=24.19, M S_{\mathrm{e}}=$ $2,585, p<.01]$, when the prime and target belonged to the same category but did not rhyme [by subjects, $F(1,78)=$ $146.007, M S_{\mathrm{e}}=462.493, p<.01$; by items, $F(1,116)=$ $\left.19.981, M S_{\mathrm{e}}=2,585, p<.01\right]$ and when the prime and target rhymed and belonged to the same category [by subjects, $F(1,78)=308.379, M S_{\mathrm{e}}=462.493, p<.01$; by items, $\left.F(1,116)=42.254, M S_{\mathrm{e}}=2,585, p<.01\right]$.

Table 2

Mean RTs (in Milliseconds) and Percent Errors Obtained in the Semantic Categorization Task for "Yes" Responses

\begin{tabular}{|c|c|c|c|c|c|c|c|c|c|c|}
\hline \multirow[b]{3}{*}{ Category } & \multicolumn{5}{|c|}{ Short SOA } & \multicolumn{5}{|c|}{ Long SOA } \\
\hline & \multicolumn{2}{|c|}{ Rhyming } & \multicolumn{2}{|c|}{ Nonrhyming } & \multirow[b]{2}{*}{ Mean RT } & \multicolumn{2}{|c|}{ Rhyming } & \multicolumn{2}{|c|}{ Nonrhyming } & \multirow[b]{2}{*}{ Mean RT } \\
\hline & RT & $\%$ Error & RT & $\%$ Error & & RT & $\%$ Error & RT & $\%$ Error & \\
\hline Same & 615 & 2.5 & 640 & 2.7 & 627 & 581 & 3.3 & 600 & 2.8 & 590 \\
\hline Different & 642 & 2.2 & 679 & 3.4 & 660 & 606 & 2.8 & 639 & 2.6 & 622 \\
\hline Mean RT & 628 & & 659 & & & 593 & & 619 & & \\
\hline
\end{tabular}


Table 3

Mean RTs (in Milliseconds) and Percent Errors Obtained

in the Rhyme Detection Task for "Yes" Responses

\begin{tabular}{|c|c|c|c|c|c|c|c|c|c|c|}
\hline \multirow[b]{3}{*}{ Category } & \multicolumn{5}{|c|}{ Short SOA } & \multicolumn{5}{|c|}{ Long SOA } \\
\hline & \multicolumn{2}{|c|}{ Rhyming } & \multicolumn{2}{|c|}{ Nonrhyming } & \multirow[b]{2}{*}{ Mean RT } & \multicolumn{2}{|c|}{ Rhyming } & \multicolumn{2}{|c|}{ Nonrhyming } & \multirow[b]{2}{*}{ Mean RT } \\
\hline & RT & $\%$ Error & RT & $\%$ Error & & RT & $\%$ Error & RT & $\%$ Error & \\
\hline Same & 526 & 1.3 & 546 & 1.4 & 536 & 491 & 1.4 & 508 & 1.4 & 499 \\
\hline Different & 542 & 1.7 & 591 & 1.2 & 566 & 505 & 1.3 & 546 & 0.8 & 525 \\
\hline Mean RT & 534 & & 568 & & & 498 & & 527 & & \\
\hline
\end{tabular}

As in Experiment 2, there were no main effects or interaction in the error analysis. Also as in Experiment 2, the error rate was extremely low (1.3\%).

\section{Discussion}

The rhyme priming effects obtained in both the semantic categorization task and the rhyme detection task further substantiate the claim that priming effects based on phonological similarity do exist. This conclusion is important because, since Hillinger (1980), there has been little evidence of priming effects using rhyme relationships, although phonological priming effects have been obtained with homophones or pseudohomophones (Humphreys et al., 1982; Lukatela \& Turvey, 1993, 1994; Perfetti et al., 1988). The fact that not only homophones but also rhymes can produce priming effects provides stronger evidence that phonological similarity in general is a basis for producing priming effects. Furthermore, the fact that those effects were observed across all three tasks and with only a brief exposure of a masked prime leads to the conclusion that the phonological processing producing those effects is automatic.

Essentially the same conclusions can be made about the obtained semantic priming effects. That is, priming effects based on semantic similarity can be obtained, and the semantic processing producing those effects appears to be automatic.

Having established that both phonological and semantic similarity can produce priming in both phonological and semantic tasks, the next question would seem to be how this occurs. One assumption that is generally made is that lexical representations have to be activated to perform a semantic task such as categorizing words. The fact that phonological similarity automatically speeds subjects' performance when they have to categorize words would be consistent with the idea that what phonological priming does is to heighten activation of lexical representations.

For example, one could start with the assumption that phonological processing mediates access to lexical representations, as suggested by results from the experiments showing associative priming mediated by phonology (Lesch \& Pollatsek, 1993; Lukatela \& Turvey, 1994). One could then argue that this prelexical processing activates lexical representations of phonologically similar words. This heightened lexical activation then allows more rapid access to the relevant semantic information. At the same time, one could make the standard argument that the semantic priming in this task was due to a spreading activation process, which also led to heightened lexical activation. As such, both priming effects in the categorization task could be accounted for.

The other component of the question, of course, is, why was there both phonological and semantic priming in the phonological task (and why was there phonological priming in the color matching task)? If phonology is generated prelexically, as suggested above, in a purely phonological task there would be no reason to expect a semantic influence. That is, to perform such a task, access to phonological representations is required, but there would be no need to access lexical representations. Thus, the semantic priming effect observed must be taken to mean that lexical representations are accessed and used in responding in this task even though the task is explicitly phonological. If so, it follows that both phonological and semantic similarity would facilitate responding. Similarly, as noted earlier, the assumption could be made that responding in the color matching task cannot be done without finishing some lexical processing on the target word. If lexical activation were heightened due to a phonologically similar prime, that processing would, presumably, be facilitated.

A final question remains, however. If both semantic and phonological similarity simply increase lexical activation, which explains the priming effects in the two tasks, why did they interact in the rhyme detection task but not in the semantic categorization task? Presumably, since the same stimuli were used in the two tasks, if the effect of both types of similarity was simply to increase lexical activation, it should have been increased to the same degree in both tasks. Hence, the priming effects should have been equivalent in the two tasks. We will return to this point in the General Discussion section.

\section{EXPERIMENT 4}

If the above analysis is correct and if the results of Experiment 1 are also explainable in terms of heightened lexical activation facilitating some necessary lexical processing, a further prediction can be made. That is, as noted, the apparent empirical parallels between phonological and semantic priming led to the theoretical claim that these effects arose from the same source. Thus, if one observes a phonological priming effect in a color 
matching task, one should also observe a semantic priming effect in a color matching task. In Experiment 4, we attempted to evaluate that prediction.

Experiment 4 also allowed us the opportunity to reexamine the effects of phonological similarity in this task. We had two reasons for doing so. As noted, the literature on this issue (e.g., Tanenhaus et al., 1980) suggests that the effects we would observe would be inhibitory rather than facilitory. We believe that we have provided an accurate account of why the differences between our manipulation and those used in previous studies led to different results. Nonetheless, it was somewhat important that we demonstrate that our novel and, to many, unintuitive result obtained in Experiment 1 replicates. Second, reexamining phonological similarity in the context of semantic similarity again allowed us to examine the question of whether these two factors interact. Thus, the results of Experiment 4 were expected to shed some further light on how one should interpret the difference between Experiments 2 and 3 .

\section{Method}

Subjects. Eighty undergraduate students from the University of Grenoble, all native French speakers, participated in this experiment for course credit. None of these subjects had participated in the previous experiments.

Stimuli. The stimuli, primes, and targets were the same as those used in Experiments 2 and 3. As in Experiment 1, "yes" targets were presented in one of five different colors. For each of these 30 "yes" targets, there was a corresponding "no" target that was presented in a different color.

Procedure. The experimental procedure was the same as that in Experiments 2 and 3 except that the first stimulus that the subjects saw was a colored square presented in the center of the screen for $1,498 \mathrm{msec}$. The task was the same as that in Experiment 1 - that is, to decide whether the target was written in the same color as the square presented at the beginning of the trial.

\section{Results}

Both mean color matching times for "yes" targets and mean error rates for "yes" targets were analyzed in the same way as in Experiments 2 and 3. Again, a main effect of SOA was observed. "Yes" targets were responded to faster with an SOA of $399 \mathrm{msec}$ than with an SOA of $147 \mathrm{msec}$. Unlike in Experiments 2 and 3, this difference was significant both by subjects $[F(1,78)=10.357$, $\left.M S_{\mathrm{e}}=177,661, p<.01\right]$ and by items $[F(1,116)=$
156.365, $\left.M S_{\mathrm{e}}=133,859, p<.01\right]$. As before, SOA did not interact with any of the other factors (see Table 4).

There was a significant main effect of semantic relatedness both by subjects $\left[F(1,78)=65.327, M S_{\mathrm{e}}=38,019\right.$, $p<.01]$ and by items $\left[F(1,116)=35.195, M S_{\mathrm{e}}=28,123\right.$, $p<.01]$. Matching the "yes" target's color with the color patch was 22 msec faster when the prime and "yes" target belonged to the same category $(398 \mathrm{msec})$ than when the prime and "yes" target belonged to different categories (420 msec).

As in Experiment 1, there was also a significant main effect of phonological relatedness both by subjects $\left[F(1,78)=50.667, M S_{\mathrm{e}}=29,184, p<.01\right]$ and by items $\left[F(1,116)=27.921, M S_{\mathrm{e}}=22,310, p<.01\right]$. Matching the "yes" target's color with the color of the patch was $19 \mathrm{msec}$ faster when the prime and "yes" target rhymed $(399 \mathrm{msec})$ than when the prime and "yes" target did not rhyme (418 $\mathrm{msec})$.

As in Experiment 3, a significant interaction between semantic and phonological relatedness was observed [by subjects, $F(1,78)=11.59, M S_{\mathrm{e}}=4,351, p<.01$; by items, $\left.F(1,116)=4.168, M S_{\mathrm{e}}=3,330, p<.05\right]$. Again, this appears to be an underadditive interaction, with the combined priming effect being smaller than the sum of the two individual effects.

As before, all three experimental conditions were significantly different from the unrelated-nonrhyme condition: when the prime and target rhymed but belonged to different categories [by subjects, $F(1,78)=74.678, M S_{\mathrm{e}}=$ $375.438, p<.01$; by items, $F(1,116)=26.831, M S_{\mathrm{e}}=$ $799.068, p<.01]$, when the prime and target belonged to the same category but did not rhyme [by subjects, $F(1,78)$ $=90.687, M S_{\mathrm{e}}=375.438, p<.01$; by items, $F(1,116)=$ $\left.31.792, M S_{\mathrm{e}}=799.068, p<.01\right]$ and when the prime and target rhymed and belonged to the same category [by subjects, $F(1,78)=178.225, M S_{\mathrm{e}}=375.438, p<.01$; by items, $\left.F(1,116)=62.906, M S_{\mathrm{e}}=799.068, p<.01\right]$.

In the error analysis, again there were no significant main effects or interactions, and the error rate was quite low $(1.4 \%)$.

\section{Discussion}

Again, a rhyme priming effect was obtained, which strengthens the conclusions that phonological priming effects are real, are obligatory, and are manifest even if

Table 4

Mean RTs (in Milliseconds) and Percent Errors Obtained in the Color Matching Task for "Yes" Responses

\begin{tabular}{|c|c|c|c|c|c|c|c|c|c|c|}
\hline \multirow[b]{3}{*}{ Category } & \multicolumn{5}{|c|}{ Short SOA } & \multicolumn{5}{|c|}{ Long SOA } \\
\hline & \multicolumn{2}{|c|}{ Rhyming } & \multicolumn{2}{|c|}{ Nonrhyming } & \multirow[b]{2}{*}{ Mean RT } & \multicolumn{2}{|c|}{ Rhyming } & \multicolumn{2}{|c|}{ Nonrhyming } & \multirow[b]{2}{*}{ Mean RT } \\
\hline & RT & $\%$ Error & RT & $\%$ Error & & RT & $\%$ Error & RT & $\%$ Error & \\
\hline Same & 417 & 1.7 & 429 & 1.5 & 423 & 367 & 1.7 & 379 & 1.3 & 373 \\
\hline Different & 428 & 1.4 & 456 & 1.0 & 442 & 385 & 1.5 & 410 & 1.2 & 397 \\
\hline Mean RT & 422 & & 442 & & & 376 & & 394 & & \\
\hline
\end{tabular}


the task has nothing to do with the phonological dimension or the semantic dimension of the word. The same conclusion about semantic processing can be drawn on the basis of the obtained semantic priming effects. Specifically and most importantly, priming effects based on semantic similarity can be observed even when phonological and semantic dimensions are not implicated in the task.

The appearance of facilitation effects, rather than interference effects, again indicates that the reason that others have observed interference effects in similar paradigms (e.g., Tanenhaus et al., 1980) is because they required subjects to produce a color naming response. In that type of task, there is a competition between two articulatory programs: the one of the word, which is automatically activated, and the one of the color. In the color matching task, there would be no reason to activate the color name, and, hence, there is neither interference in general nor any additional interference from a target following a related prime.

Finally, the appearance of a semantic priming effect in this task provides the firmest support yet for the conclusion that priming effects in the color matching task derive from the activation of lexical representations. That is, while it might be possible to explain phonological priming in this task in terms of activating prelexical phonological representations, it would be quite difficult to explain semantic priming in that same way.

\section{EXPERIMENT 5}

The patterns of priming reported thus far are quite consistent with the conclusion that at least some lexical processing is required in all of these tasks and that both phonologically and semantically related primes facilitate that processing. However, one could also argue that the observed priming effects have emerged from another stage of processing - that is, the decision stage. For example, in Experiment 4, the trials in which there was either a phonological or a semantic relationship between the prime and target were also trials in which the target's color matched the color of the square. Thus, when the prime and target were related, the correct answer was always "yes." In this situation, one could argue that if the subjects had noticed a relationship between primes and targets (assuming that they were even able to see the primes), it could have biased them toward making a "yes" response, thereby artificially producing a priming effect. A similar situation also existed in Experiments 2 and 3 . In those experiments, related primes and target were also presented only on "positive" trials.

For a strategy of this sort to be used, of course, the subjects had to have been conscious (1) of the primes, (2) of the two different relationships (phonological and semantic) between those primes and the targets, and (3) of the fact that the existence of a relationship was predictive of the nature of the response. As such, this type of explanation does not seem to be a very likely one because, in the previous experiments, (1) the primes were briefly presented and masked, (2) there was not a large percentage of related prime-target pairs (less than 38\% counting both phonologically related pairs and semantically related pairs), and (3) the entire experiment consisted of only 60 trials, suggesting that most of the experiment would have been over by the time that the subjects could have put this knowledge to use. Nonetheless, at present, we have no data that would allow this particular explanation to be completely ruled out. As such, in Experiment 5, we attempted to evaluate this explanation.

The task used in Experiment 5 was a color matching task, and the "no" trials also involved both semantic and phonological relationships between primes and targets. As such, the existence of a prime-target relationship was not predictive of the correct response. Thus, any priming observed on "yes" trials could not be attributed to a decision strategy. Note also that our hypothesis that a relationship between primes and targets expedites lexical processing and, hence, allows decision making to begin more quickly makes a further prediction: The same pattern of priming effects found on "yes" trials should also be found on "no" trials.

\section{Method}

Subjects. Forty-eight undergraduate students from the University of Grenoble, all native French speakers, participated in the experiment. None of them had participated in the previous experiments.

Stimuli. The targets were 40 frequent words (always displayed in one of five possible colors). Twenty of these were selected to be "yes" targets, and 20 were selected to be "no" targets. For each target, four different prime words, defined in terms of whether or not the prime had a phonological relationship with the target and whether or not the prime had a semantic relationship with the target, were selected. Thus, as in Experiments 2-4, there were four experimental conditions: (1) a related-rhyme condition, (2) a related-nonrhyme condition, (3) an unrelated-rhyme condition, and (4) an unrelatednonrhyme condition (see Appendix D). Prime frequency, target frequency, and OS between primes and targets were controlled in a similar way as in the previous experiments.

Four lists of 40 trials were created by combining primes and targets; a trial consisted of a colored square, a prime, a mask, and a target. For each list, 20 targets ("yes" targets) were written in the same color as the colored square, and 20 ("no" targets) were written in a different color than the colored square. For each list, (1) 10 targets (5 "yes" and 5 "no") were preceded by a related-rhyming prime, (2) 10 targets (5 "yes" and 5 "no") were preceded by a related-nonrhyming prime, (3) 10 targets (5 "yes" and 5 "no") were preceded by an unrelated-rhyming prime, and (4) 10 targets (5 "yes" and 5 "no") were preceded by an unrelated-nonrhyming prime. It should be noted, then, that the primes shared a phonological or semantic relationship with "no" targets and with "yes" targets. As in the previous experiments, targets preceded by one kind of prime in one list were preceded by another kind in the other lists. The presentation order of the 40 trials followed the same constraints as in Experiments 2-4.

Procedure. The experimental procedure was the same as that in Experiment 4 except that only the short SOA $(147 \mathrm{msec})$ was used here. The task was the same as that in Experiments 1 and 4 that is, to decide whether the target was written in the same color as the square presented at the beginning of the trial.

\section{Results}

Both mean color matching times for "yes" and "no" targets and mean error rates for "yes" and "no" targets 
Table 5

Mean RTs (in Milliseconds) and Percent Errors Obtained in the Color Matching Task for "Yes" and "No" Responses

\begin{tabular}{|c|c|c|c|c|c|c|c|c|c|c|}
\hline \multirow[b]{3}{*}{ Category } & \multicolumn{5}{|c|}{ "Yes" Targets } & \multicolumn{5}{|c|}{ "No" Targets } \\
\hline & \multicolumn{2}{|c|}{ Rhyming } & \multicolumn{2}{|c|}{ Nonrhyming } & \multirow[b]{2}{*}{ Mean RT } & \multicolumn{2}{|c|}{ Rhyming } & \multicolumn{2}{|c|}{ Nonrhyming } & \multirow[b]{2}{*}{ Mean RT } \\
\hline & $\overline{\mathrm{RT}}$ & $\%$ Error & RT & $\%$ Error & & RT & $\%$ Error & RT & $\%$ Error & \\
\hline Same & 419 & 4.4 & 430 & 5.0 & 424 & 451 & 4.2 & 458 & 4.4 & 454 \\
\hline Different & 429 & 5.0 & 454 & 4.2 & 441 & 462 & 4.2 & 482 & 4.4 & 472 \\
\hline Mean RT & 424 & & 442 & & & 456 & & 470 & & \\
\hline
\end{tabular}

were analyzed. Two ANOVAs, one treating subjects as a random factor and one treating items as a random factor, were carried out. In all ANOVAs, the factors were response (yes vs. no), phonological relatedness, and semantic relatedness.

With respect to the response factor, color matching times were $30 \mathrm{msec}$ shorter for "yes" targets $(433 \mathrm{msec})$ than for "no" targets (463 msec); this difference was significant both by subjects $\left[F(1,47)=28.03, M S_{\mathrm{e}}=88,912\right.$, $p<.01]$ and by items $\left[F(1,32)=142.18, M S_{\mathrm{e}}=9,225\right.$, $p<.01]$. The response factor did not interact with any other factors (all $F \mathrm{~s}<1.90$ ).

A significant effect of semantic relatedness was obtained both by subjects $\left[F(1,47)=71.93, M S_{\mathrm{e}}=29,966\right.$, $p<.01]$ and by items $\left[F(1,32)=50.15, M S_{\mathrm{e}}=3254, p<\right.$ $.01]$. Matching a target's color with the colored square was $18 \mathrm{msec}$ faster when the prime and target belonged to the same category $(439 \mathrm{msec})$ than when the prime and target belonged to different categories ( $457 \mathrm{msec})$.

As in Experiment 4, there was also a significant main effect of phonological relatedness both by subjects $\left[F(1,47)=41.72, M S_{\mathrm{e}}=23,904, p<.01\right]$ and by items $\left[F(1,32)=40.26, M S_{\mathrm{e}}=2,612, p<.01\right]$. Matching a target's color with the colored square was $16 \mathrm{msec}$ faster when the prime and target rhymed $(440 \mathrm{msec})$ than when the prime and target did not rhyme $(456 \mathrm{msec})$.

A significant underadditive interaction between semantic relatedness and phonological relatedness was observed [by subjects, $F(1,47)=13.06, M S_{\mathrm{e}}=4,624, p<$ .01 ; by items, $\left.F(1,32)=5.99, M S_{\mathrm{e}}=389, p<.05\right]$. (See Table 5.)

As in Experiment 4, all three experimental conditions were significantly different from the unrelated-nonrhyme condition: when the prime and target rhymed but belonged to different semantic categories [by subjects, $F(1,47)=$ $69.99, M S_{\mathrm{e}}=354, p<.01$; by items, $F(1,32)=38.67$, $\left.M S_{\mathrm{e}}=64, p<.01\right]$, when the prime and target belonged to the same category but did not rhyme [by subjects, $F(1,47)=82.10, M S_{\mathrm{e}}=354, p<.01$; by items, $F(1,32)=$ $\left.45.42, M S_{\mathrm{e}}=64, p<.01\right]$ and when the prime and target rhymed and belonged to the same category [by subjects, $F(1,47)=151.69, M S_{\mathrm{e}}=354, p<.01 ;$ by items, $F(1,32)$ $\left.=90.15, M S_{\mathrm{e}}=64, p<.01\right]$.

In the error analysis, there were no significant main effects or interactions. The error rate was again somewhat small $(4.47 \%)$.

\section{Discussion}

Again, both a rhyme priming effect and a semantic priming effect were obtained. More importantly, however, those facilitation effects were independent of the nature of the response: Priming effects were observed on both "yes" and "no" trials. This result provides strong evidence against the idea that the priming effects reported in the previous experiments were due to a bias during the decision-making process. Thus, the phonological and semantic facilitation effects observed on "no" trials strongly supports the conclusion that those effects do not emerge from a decision-making strategy but rather are due to the results of automatic activation.

The fact that semantic priming effects were again observed in the color matching task suggests that the automatic processing that drives the priming is most likely lexical in nature. Taken together, these data lead to the conclusion that the two effects emerge, at least partially, from a common stage of processing, presumably one involving lexical representations. Finally, the conclusion that lexical processing is required to perform a color matching task is again reinforced.

\section{GENERAL DISCUSSION}

The results of the present experiments can be summed up quite succinctly. Briefly presented, masked primes produce both semantic and phonological priming effects across a wide variety of tasks. These effects emerged in a semantic judgment task, in a phonological judgment task, and even in a color matching task in spite of the fact that no stored memorial information of any sort (lexical, phonological, or semantic) is necessary in order to respond in that task.

We have attempted to explain these results at a general level by suggesting that the effect of prime processing is to activate lexical structures for words both phonologically and semantically similar to the prime. Once activated, processing of those words at the lexical level is facilitated. We have further concluded that all these tasks, even the color matching task, require at least some amount of lexical processing. In Experiment 5, we explicitly tested an alternative hypothesis, that these priming effects were merely decision-making effects. Although only the color matching task was used, the results-that is, phonological and semantic priming effects for both 
"yes" and "no" responses-would appear to rule out any account based on the decision-making process.

Before discussing possible theoretical accounts, two issues need further comment. The first is the interaction between semantic and phonological priming effects. This interaction was not significant in Experiment 2; however, it was significant in Experiments 3, 4, and 5. In all four experiments, however, it always took an underadditive form, in that the combined effects of semantic and phonological relationships were smaller than the sum of the two effects. The basic conclusion we have reached, that semantic and phonological relatedness both facilitate lexical processing, would be quite consistent with an interactive relationship, since both factors affect the same stage (e.g., see Sternberg, 1969). Furthermore, the particular form of this interaction would appear to indicate that there may be some asymptotic limit to the amount of lexical activation that multiple sources of activation can produce. What should also be noted, of course, is that because this interaction was underadditive, it may reflect nothing more than a floor effect in the semantically and phonologically related condition. As such, at present, it does not appear that any firm conclusions should be drawn from this pattern of interaction.

Second, throughout the paper, we have argued that the observed priming effects are the results of automatic processing. This argument was based on a number of considerations. First, the prime was briefly presented and was masked. Second, the SOA was quite short $(<150 \mathrm{msec})$, meaning that there was very little time to execute any expectancy strategies on any trials when the prime was perceived. Third, at least in Experiments 1-4, the percentage of related trials was always less than $50 \%$ and the percentage of a particular type of related trial was never more than $33 \%$. Thus, expectancy strategies would not tend to have produced much in the way of a payoff. Fourth, the total number of trials was never more than 60 . Thus, assuming that it would have taken the subjects some time to discover any effective strategies, the number of trials remaining on which that strategy could have been implemented would have been rather small. The results of Experiment 5 allowed us to add another consideration to that list: Eliminating the usefulness of a possible decisionmaking strategy did not change the pattern of results, implying that this strategy had very likely not been in place in the earlier experiments in any case. We acknowledge that these arguments do not conclusively prove that these effects were automatic rather than due to subject strategies. Nonetheless, keeping these considerations in mind, we are at a loss to come up with any viable strategic account of our priming effects.

\section{Theories of Priming}

According to Collins and Loftus (1975), semantic priming effects can be explained in terms of a spreading activation process. That is, concepts are represented by local nodes in a semantic network, and, when a concept is processed, its activation spreads out along the network to nodes for semantically similar concepts. Concepts' names are also represented by local nodes in another network, the lexical network, which is organized along lines of phonological similarity. When a lexical node is activated, its activation spreads out along the network to nodes for words that are phonologically similar.

This spreading activation theory can explain both semantic and phonological priming effects in a way that is essentially task independent. Semantic priming effects in a phonological task, such as our rhyme detection task, would emerge from a two-step process: the spreading of activation within the semantic network that leads to heightened activation of and, hence, more rapid access to the target's lexical node due to the connections between the semantic and lexical networks. The phonological priming effects in a semantic task, such as our categorization task, would emerge from the spread of activation within the lexical network that leads to a heightened activation of the target's lexical node, which eases access to both the target's lexical and semantic nodes. It appears, then, that the data reported here are relatively well explained by this theory.

What is not entirely clear, however, is whether this explanation would get all the details right. For example, if cross-network priming effects really do derive from a two-step process and within-network priming effects from a one-step process, as suggested by Collins and Loftus's (1975) theory, one might expect that within-network priming would be stronger than between-network priming rather than being virtually identical in size, as was observed here. Thus, before concluding that this account is the superior one, one must also consider how well these effects can be explained by other theories.

A number of alternative explanations of priming effects have been developed. According to one of these theories, the compound cue theory (McKoon \& Ratcliff, 1992; Whittlesea \& Jacoby, 1990), a prime and target may be combined during encoding leading to a compound cue. The degree of familiarity of the compound cue is then assumed to be used in making a decision about the target. When prime and target are related, the compound cue has a high degree of familiarity, which speeds the decision latency by biasing that process in a particular direction (i.e., typically toward a "word" response in a lexical decision task). In other words, according to this theory, priming effects emerge at the decision level. As such, it appears that the compound cue theory would not provide a particularly good account of the priming effects observed here, because those effects appear to be independent of the nature of the decision subjects are required to make. Thus, as noted, this result, obtained in Experiment 5, in fact provides clear evidence against any kind of account that would regard the decision-making stage as the source of these priming effects.

As we have argued above, for a number of reasons, we consider it unlikely that the phonological and semantic priming effects reported here are at all strategic. Therefore, any models in which priming effects are explained 
in terms of strategic processes (e.g., Neely, Keefe, \& Ross's, 1989, expectancy model) would not appear to provide a good account of these results. Thus, any viable explanation of the obtained effects would, necessarily, need to be based on automatic activation of processing structures. What is less clear, of course, is whether these must necessarily be the precise structures postulated by Collins and Loftus (1975). In particular, one could raise the question of whether an account of these data must be based on activation of lexical units.

One could, for example, ask whether an explanation of the present data could be framed in terms of PDP models, models that have distributed rather than local lexical representations. In order for a generic PDP model to account for the obtained priming effects, it must first possess both phonological and semantic processing units. As such, the earlier models (e.g., Seidenberg \& McClelland, 1989) would have no obvious mechanism for explaining semantic priming effects, because semantic units were not implemented in those models. In contrast, Masson's (1995) distributed memory model does have both of these types of units and, thus, may be able to explain both phonological and semantic priming (although only semantic priming effects have, at present, been simulated by the model). Moreover, because phonological and semantic processing units are fully interconnected, Masson's model may be able to account for any interaction between phonological and semantic structures.

How does this distributed memory model explain priming effects? According to the model, presentation of a prime automatically creates a pattern of activation across semantic and phonological processing units. If this prime is semantically similar to the target, the pattern of activation of the semantic units is similar to that of the upcoming related target. When the target is presented, activation of its pattern across the semantic units is then very fast. This fast activation of the target's semantic pattern speeds up any semantically based response about this target. This rapid activation of the target's semantic pattern would also appear to speed up phonological processing (and, hence, any responses based on phonological processing). That is, because of the full connection between semantic and phonological processing units, the pattern of activation across the semantic units can help drive the phonological units to the target's pattern. In a similar way, if the prime is phonologically similar to the target, the pattern of activation across phonological units for the prime is similar to that of the upcoming target, which can speed up either a phonologically based or a semantically based response to the target.

As with the Collins and Loftus (1975) model, this interpretation would seem to be able to give a reasonably good account of phonological and semantic priming effects in general. Nonetheless, also like the Collins and Loftus model, this explanation may have some difficulty getting all the details right. That is, Masson's (1995) distributed memory model would seem to predict that the phonological priming effect should be larger than the semantic priming effect in a phonological task, and vice versa, because the impact of one set of units (e.g., phonological units) on the other set of units (e.g., semantic units) is certainly more indirect than the impact of a set of units on itself would be. This problem is magnified when considering the effects in a phonological task because of the assumed time difference in activating the two patterns. That is, because the semantic pattern is presumed to be activated more slowly than the phonological pattern, it seems even less likely that the model would be able to predict equivalent-sized phonological and semantic priming effects in a phonological task. Finally, it should also be noted that this model would not necessarily predict the phonological and semantic priming effects observed in the color matching tasks. Instead, like with the Collins and Loftus model, the assumption would have to be made that responding in that task would require the completion of some lexical (or higher) level processing. One might need to assume, for example, that both phonological and semantic representations must be nearly fully established before subjects are able to devote sufficient attention to the color matching task.

\section{Conclusions}

The results reported in the present paper support a structural account of priming effects in which priming is due to some sort of activation process. As such, both Collins and Loftus's (1975) spreading activation model and Masson's (1995) distributed memory model have some of the ability to account for both the direct priming effects and the cross-network priming effects. Nonetheless, these models also appear to have some of the same limitations: They provide no particular account for priming effects obtained in color matching tasks, and they may have some difficulty accounting for the similar size of phonological and semantic priming effects. As such, it appears that these data would have little to say about the distributed versus local debate about the nature of representations. What they do indicate, however, is that regardless of how one wishes to conceptualize phonological and semantic representations, these representations do not exist in isolation from one another. Rather, activation in one system clearly leads to activation in the other even when that activation is driven only by automatic processing.

\section{REFERENCES}

Collins, A. M. \& LofTus, E. F. (1975). A spreading-activation theory of semantic processing. Psychological Review, 82, 407-428.

Content, A., Mousty, P., \& Radeau, M. (1990). Brulex: Une base de données lexicales informatisée pour le français écrit et parlé. [Brulex: A computerized lexical database for written and spoken French]. L'Année Psychologique, 90, 551-566.

Ferrand, L., \& Grainger, J. (1992). Phonology and orthography in visual word recognition: Evidence from masked non-word priming. Quarterly Journal of Experimental Psychology, 45A, 353-372. 
FLEMING, K. K. (1993). Phonologically mediated priming in spoken and printed word recognition. Journal of Experimental Psychology: Learning, Memory, \& Cognition, 19, 272-284.

FORSTER, K. I. (1976). Accessing the mental lexicon. In R. J. Wales \& E. W. Walker (Eds.), New approaches to language mechanisms (pp. 257-287). Amsterdam: North-Holland.

Frost, R., \& BENTIN, S. (1992). Processing phonological and semantic ambiguity: Evidence from semantic priming at different SOAs. Journal of Experimental Psychology: Learning, Memory, \& Cognition, $18,58-68$

Hillinger, M. L. (1980). Priming effects with phonemically similar words: The encoding-bias hypothesis reconsidered. Memory \& Cognition, 8, 115-123.

Holender, D. (1986). Semantic activation without conscious identification in dichotic listening, parafoveal vision, and visual masking: A survey and appraisal. Behavioral \& Brain Sciences, 9, 1-66.

Humphreys, G. W., EvetT, L. J., \& TAYLOR, D. E. (1982). Automatic phonological priming in visual word recognition. Memory \& Cognition, 10, 576-590.

LesCh, M. F., \& Pollatsek, A. (1993). Automatic access of semantic information by phonological codes in visual word recognition. Journal of Experimental Psychology: Learning, Memory, \& Cognition, 19, 285-294.

Lukatela, G., Carello, C., \& Turvey, M. T. (1990). Phonemic priming by words and pseudowords. European Journal of Cognitive Psychology, 2, 375-394.

Lukatela, G., \& Turvey, M. T. (1990a). Automatic and prelexical computation of phonology in visual word identification. European Journal of Cognitive Psychology, 2, 325-344.

Lukatela, G., \& Turvey, M. T. (1990b). Phonemic similarity effects and prelexical phonology. Memory \& Cognition, 18, 128-152.

Lukatela, G., \& Turvey, M. T. (1991). Phonological access of the lexicon: Evidence from associative priming with pseudohomophones. Journal of Experimental Psychology: Human Perception \& Performance, 17, 951-966.

Lukatela, G., \& TuRvey, M. T. (1993). Similar attentional, frequency, and associative effects for pseudohomophones and words. Journal of Experimental Psychology: Human Perception \& Performance, 19, 166-178.

Lukatela, G., \& Turvey, M. T. (1994). Visual lexical access is initially phonological: 1 . Evidence from associative priming by words, homophones, and pseudohomophones. Journal of Experimental Psychology: General, 123, 107-128.

MARCEL, A. J. (1983). Conscious and unconscious perception: Experiments on visual masking and word recognition. Cognitive Psychology, 15, 197-237.

Martin, R. C., \& Jensen, C. R. (1988). Phonological priming in the lexical decision task: A failure to replicate. Memory \& Cognition, 16, 505-521.

MAsson, M. E. J. (1995). A distributed memory model of semantic priming. Journal of Experimental Psychology: Learning, Memory, \& Cognition, 21, 3-23.

MCKOON, G., \& RATCLIFF, R. (1992). Spreading activation versus compound cue accounts of priming: Mediated priming revisited. Journal of Experimental Psychology: Learning, Memory, \& Cognition, 18, $1155-1172$.

Meyer, D. E., Schvaneveldt, R. W., \& Ruddy, M. G. (1974). Functions of graphemic and phonemic codes in visual word recognition. Memory \& Cognition, 2, 309-321.

Neely, J. H., KeEFE, D. E., \& Ross, K. L. (1989). Semantic priming in the lexical decision task: Roles of prospective prime-generated expectancies and retrospective semantic matching. Journal of Experimental Psychology: Learning, Memory, \& Cognition, 15, 1003 1019.

Perfetti, C. A., \& Bell, L. C. (1991). Phonemic activation during the first $40 \mathrm{msec}$ of word identification: Evidence from backward masking and priming. Journal of Memory \& Language, 30, 473-485.

Perfetti, C. A., Bell, L. C., \& Delaney, S. (1988). Automatic (prelexical) phonetic activation in silent reading: Evidence from backward masking. Journal of Memory \& Language, 27, 59-70.

Peter, M., Lukatela, G., \& Turvey, M. T. (1990). Phonological priming: Failure to replicate in the rapid naming task. Bulletin of the Psychonomic Society, 28, 389-392.

Seidenderg, M. S., \& MCClelland, J. L. (1989). A distributed, developmental model of word recognition and naming. Psychological Review, 96, 523-568.

STERNBERG, S. (1969). The discovery of processing stages: Extensions of Donder's method. Acta Psychologica, 30, 276-315.

STROOP, J. R. (1935). Studies of interference in serial verbal reactions. Journal of Experimental Psychology, 18, 643-661.

Tanenhaus, M. K., Flanigan, H. P., \& Seidenberg, M. S. (1980). Orthographic and phonological activation in auditory and visual word recognition. Memory \& Cognition, 8, 513-520.

VAN ORDEN, G. C. (1984). A ROWS is a /ROZ/ is a ROSE: Visual, phonological, developmental and strategic influences upon lexical access. Unpublished doctoral dissertation, University of California, San Diego.

VAN ORDEN, G. C. (1987). A ROWS is a ROSE: Spelling, sound, and reading. Memory \& Cognition, 15, 181-198.

WEBER, R. M. (1970). A linguistic analysis of first-grade reading errors. Reading Research Quarterly, 5, 427-451

Whittlesea, B. W. A., \& JACOBY, L. L. (1990). Interaction of prime repetition with visual degradation: Is priming a retrieval phenomenon? Journal of Memory \& Language, 29, 546-565.

\section{NOTES}

1. It should be noted that this way of defining a rhyme relationship between two words is the classical way to do so in the French language. That is, in French, two words that share the same phonology in their last syllable are considered to be rhyming words.

2. As noted by one of the reviewers, the orthographic control condition is only as good as the OS formula is. We believe that the OS formula quantifies many, if not most, of what we take to be the relevant characteristics of orthographic similarity. As such, we have every confidence that it is measuring what it is supposed to measure.

3. With this kind of computer, the time needed for one screen scan is $7 \mathrm{msec}$, so all the stimuli presentation times were proportional to this number, and all were constrained by it--that is, when we say that a stimulus was presented for $x$ msec, it means that it was presented for $x \pm$ $7 \mathrm{msec}$.

\section{APPENDIX A}

The experiments reported here required a control of orthographic similarity between primes and targets. For this purpose, we adapted a measure from Weber (1970), which was also used by Van Orden $(1984,1987)$. Van Orden's measure of orthographic similarity (OS) is computed by the following ratio:

$\mathrm{OS}=(\mathrm{GS}$ of the word to be compared and the reference word $) /$

(GS of the reference word and itself),

where GS is the graphic similarity defined by Weber as follows:

$$
\mathrm{GS}=10([(50 \mathrm{~F}+30 \mathrm{~V}+10 \mathrm{C}) / \mathrm{A}]+5 \mathrm{~T}+27 \mathrm{~B}+18 \mathrm{E}),
$$

where $\mathrm{F}=$ number of pairs of adjacent letters in the same order shared by word pairs, $V=$ number of pairs of adjacent letters in reverse order shared by word pairs, $\mathrm{C}=$ number of single letters shared by word pairs, $\mathrm{A}=$ average number of letters in the two words, $T=$ ratio of number of letters in the shorter word to the number in the longer, $\mathrm{B}=1$ if the first letter in the two words is the same, otherwise $B=0$, and $E=1$ if the last letter in the two words is the same, otherwise $\mathrm{E}=0$. 
APPENDIX B

Prime-"Yes" Target Pairs Used in Experiment 1 and Their Orthographic Similarity (OS)

\begin{tabular}{|c|c|c|c|c|c|}
\hline \multicolumn{2}{|c|}{ Phonological Condition } & \multicolumn{2}{|c|}{ Orthographic Control Condition } & \multicolumn{2}{|c|}{ Unrelated Control Condition } \\
\hline Prime-"Yes" Target & $0 \mathrm{~S}$ & Prime-"Yes" Target & OS & Prime-"Yes" Target & $0 \mathrm{~S}$ \\
\hline asticot-artichaud & .47 & audition-artichaud & .56 & cabanon-artichaud & .07 \\
\hline couchette-noisette & .54 & ardoise-noisette & .46 & chaudière-noisette & .25 \\
\hline chignon-champignon & .51 & strapontin-champignon & .35 & orteil-champignon & .05 \\
\hline litron-poivron & .43 & pourvoi-poivron & .57 & lustre-poivron & .06 \\
\hline chanson-jambon & .34 & tambour-jambon & .33 & plateau-jambon & .06 \\
\hline sergent-pellican & .07 & pastille-pellican & .55 & berceau-pellican & .08 \\
\hline buvard-lézard & .44 & larron-lézard & .45 & hublot-lézard & .07 \\
\hline pétard-canard & .44 & carnet-canard & .54 & rétine-canard & .08 \\
\hline drapeau-chameau & .42 & cauchemar-chameau & .56 & bouton-chameau & .06 \\
\hline sapin-requin & .35 & banquier-requin & .30 & habit-requin & .06 \\
\hline crottin-poussin & .33 & roussi-poussin & .46 & dortoir-poussin & .08 \\
\hline coupon-cochon & .77 & console-cochon & .56 & déchet-cochon & .16 \\
\hline poirier-cahier & .41 & hiver-cahier & .47 & neveu-cahier & .06 \\
\hline panier-sablier & .43 & salaire-sablier & .51 & copain-sablier & .07 \\
\hline anémone-trombone & .50 & tribord-trombone & .52 & gladiateur-trombone & .07 \\
\hline corbeau-stylo & .05 & bestiole-stylo & .22 & platane-stylo & .07 \\
\hline réveil-oreille & .34 & peintre-oreille & .42 & statue-oreille & .23 \\
\hline douceur-chasseur & .40 & duchesse-chasseur & .37 & falaise -chasseur & .15 \\
\hline saveur--voleur & .46 & voyelle-voleur & .56 & bonnet-voleur & .08 \\
\hline soutien-magicien & .39 & cinéma-magicien & .34 & salade-magicien & .06 \\
\hline échiquier -policier & .38 & domicile-policier & .35 & parapet-policier & .34 \\
\hline zéro-vélo & .29 & voilier-vélo & .38 & pâté-vélo & .08 \\
\hline union-camion & .46 & caillou-camion & .44 & musée-camion & .06 \\
\hline pruneau-bateau & .41 & grabat-bateau & .33 & fourmi-bateau & .07 \\
\hline paupière-teillière & .50 & abeille-teillière & .56 & réchaud-teillière & .16 \\
\hline bouleau-couteau & .50 & contour-couteau & .51 & guitare-couteau & .10 \\
\hline sonnette-fourchette & .52 & roulotte-fourchette & .50 & guenille-fourchette & .24 \\
\hline tombeau-manteau & .43 & diamant-manteau & .37 & torrent-manteau & .16 \\
\hline banquette-chaussette & .52 & fausseté-chaussette & .70 & bonhomme-chaussette & .23 \\
\hline chevelure-ceinture & .64 & meringue-ceinture & .39 & bagage-ceinture & .22 \\
\hline$M$ & .42 & & .45 & & .12 \\
\hline$S D$ & .14 & & .11 & & .08 \\
\hline
\end{tabular}


APPENDIX C

Prime-“Yes" Target Pairs Used in Experiments 2-4 and Their Orthographic Similarity (OS)

\begin{tabular}{|c|c|c|c|c|c|c|c|}
\hline \multicolumn{4}{|c|}{ Same Category } & \multicolumn{4}{|c|}{ Different Category } \\
\hline \multicolumn{2}{|l|}{ Rhyming } & \multicolumn{2}{|l|}{ Nonrhyming } & \multicolumn{2}{|l|}{ Rhyming } & \multicolumn{2}{|l|}{ Nonrhyming } \\
\hline Prime-"Yes" Target & OS & Prime-"Yes" Target & OS & Prime-" Yes" Target & OS & Prime "Yes" Target & OS \\
\hline abricot-artichaud & .42 & asperge-artichaud & .32 & asticot-artichaud & .47 & cabanon-artichaud & .07 \\
\hline courgette-noisette & .54 & châtaigne-noisette & .26 & couchette-noisette & .54 & chaudière-noisette & .25 \\
\hline oignon-champignon & .59 & cerise-champignon & .31 & chignon-champignon & .51 & orteil-champignon & .05 \\
\hline citron-poivron & .43 & raisin-poivron & .26 & litron-poivron & .43 & lustre poivron & .06 \\
\hline poisson-jambon & .32 & framboise-jambon & .28 & chanson jambon & .34 & plateau-jambon & .06 \\
\hline serpent-pellican & .15 & abeille-pellican & .29 & sergent-pellican & .07 & berceau pellican & .08 \\
\hline homard-lézard & .44 & lièvre-lézard & .36 & buvard-lézard & .44 & hublot-lézard & .07 \\
\hline renard-canard & .59 & crapaud-canard & .41 & pétard-canard & .44 & rétine-canard & .08 \\
\hline taureau-chameau & .49 & colombe-chameau & .35 & drapeau-chameau & .42 & bouton-chameau & .06 \\
\hline lapin-requin & .35 & raton-requin & .52 & sapin-requin & .35 & habit-requin & .06 \\
\hline dauphin-poussin & .35 & moustique-poussin & .21 & crottin-poussin & .33 & dortoir-poussin & .08 \\
\hline dindon-cochon & .34 & chacal-cochon & .45 & coupon-cochon & .77 & déchet-cochon & .16 \\
\hline encrier-cahier & .43 & calepin-cahier & .44 & poirier-cahier & .41 & neveu-cahier & .06 \\
\hline papier-sablier & .43 & tableau-sablier & .25 & panier-sablier & .43 & copain-sablier & .07 \\
\hline téléphone-trombone & .63 & signature-trombone & .26 & anémone-trombone & .50 & gladiateur-trombone & .07 \\
\hline ciseaux-stylo & .05 & gomme-stylo & .07 & corbeau-stylo & .05 & platane-stylo & .07 \\
\hline orteil-oreille & .61 & rétine-oreille & .36 & réveil-oreille & .34 & statue oreille & .23 \\
\hline danseur-chasseur & .48 & fermier-chasseur & .24 & douceur-chasseur & .40 & falaise-chasseur & .15 \\
\hline nageur-voleur & .44 & voyant-voleur & .43 & saveur-voleur & .46 & bonnet-voleur & .08 \\
\hline indien-magicien & .41 & maquilleur-magicien & .40 & soutien-magicien & .39 & salade-magicien & .06 \\
\hline cuisinier-policier & .38 & coiffeur-policier & .28 & échiquier-policier & .38 & parapet-policier & .34 \\
\hline moto-vélo & .26 & taxi-vélo & .05 & zéro-vélo & .29 & pâté-vélo & .08 \\
\hline avion-camion & .48 & cargo-camion & .45 & union-camion & .46 & musée-camion & .06 \\
\hline landau-bateau & .43 & bagnole-bateau & .42 & pruneau-bateau & .41 & fourmi-bateau & .07 \\
\hline cuillère-teillère & .70 & tasse-teillère & .48 & paupière-teillère & .50 & réchaud-teillère & .16 \\
\hline rouleau-couteau & .50 & carafe-couteau & .35 & bouleau-couteau & .50 & guitare-couteau & .10 \\
\hline assiette-fourchette & .51 & glacière-fourchette & .25 & sonnette-fourchette & .52 & guenille-fourchette & .24 \\
\hline chapeau-manteau & .42 & culotte-manteau & .16 & tombeau-manteau & .43 & torrent-manteau & .16 \\
\hline casquette-chaussette & .80 & babouche-chaussette & .32 & banquette--chaussette & .52 & bonhomme-chaussette & .23 \\
\hline chaussure-ceinture & .63 & chandail-ceinture & .34 & chevelure-ceinture & .64 & bagage-ceinture & .22 \\
\hline$M$ & .45 & & .32 & & .42 & & .12 \\
\hline$S D$ & .15 & & .11 & & .14 & & .08 \\
\hline
\end{tabular}


APPENDLX D

Prime-Target Pairs Used in Experiment 5 and Their Orthographic Similarity (OS)

\begin{tabular}{|c|c|c|c|c|c|c|c|}
\hline \multicolumn{4}{|c|}{ Same Category } & \multicolumn{4}{|c|}{ Different Category } \\
\hline \multicolumn{2}{|l|}{ Rhyming } & \multicolumn{2}{|l|}{ Nonrhyming } & \multicolumn{2}{|l|}{ Rhyming } & \multicolumn{2}{|l|}{ Nonrhyming } \\
\hline Prime-Target & $\mathrm{OS}$ & Prime-Target & OS & Prime-Target & OS & Prime-Target & OS \\
\hline abricot-artichaud & .42 & asperge-artichaud & .32 & asticot-artichaud & .47 & cabanon-artichaud & .07 \\
\hline courgette-noisette & .54 & châtaigne-noisette & .26 & couchette-noisette & .54 & chaudière-noisette & .25 \\
\hline oignon-champignon & .59 & cerise-champignon & .31 & chignon-champignon & .51 & orteil-champignon & .05 \\
\hline citron-poivron & .43 & raisin-poivron & .26 & litron-poivron & .43 & lustre-poivron & .06 \\
\hline poisson-jambon & .32 & framboise-jambon & .28 & chanson-jambon & .34 & plateau-jambon & .06 \\
\hline serpent-pellican & .15 & abeille-pellican & .29 & sergent-pellican & .07 & berceau-pellican & .08 \\
\hline homard-lézard & .44 & lièvre-lézard & .36 & buvard-lézard & .44 & hublot-lézard & .07 \\
\hline renard-canard & .59 & crapaud-canard & .41 & pétard-canard & .44 & rétine-canard & .08 \\
\hline taureau-chameau & .49 & colombe-chameau & .35 & drapeau-chameau & .42 & bouton-chameau & .06 \\
\hline lapin-requin & .35 & raton-requin & .52 & sapin-requin & .35 & habit-requin & .06 \\
\hline dauphin-poussin & .35 & moustique-poussin & .21 & crottin-poussin & .33 & dortoir-poussin & .08 \\
\hline dindon-cochon & .34 & chacal-cochon & .45 & coupon-cochon & .77 & déchet-cochon & .16 \\
\hline encrier-cahier & .43 & calepin-cahier & .44 & poirier-cahier & .41 & neveu-cahier & .06 \\
\hline papier-sablier & .43 & tableau-sablier & .25 & panier-sablier & .43 & copain-sablier & .07 \\
\hline téléphone-trombone & .63 & signature-trombone & .26 & anémone-trombone & .50 & gladiateur-trombone & .07 \\
\hline ciseaux-stylo & .05 & gomme-stylo & .07 & corbeau-stylo & .05 & platane-stylo & .07 \\
\hline orteil-oreille & .61 & rétine-oreille & .36 & réveil-oreille & .34 & statue-oreille & .23 \\
\hline danseur-chasseur & .48 & fermier-chasseur & .24 & douceur-chasseur & .40 & falaise-chasseur & .15 \\
\hline nageur-voleur & .44 & voyant-voleur & .43 & saveur-voleur & .46 & bonnet-voleur & .08 \\
\hline indien-magicien & .41 & maquilleur-magicien & .40 & soutien-magicien & .39 & salade-magicien & .06 \\
\hline cuisinier-policier & .38 & coiffeur-policier & .28 & échiquier-policier & .3 & parapet-policier & .34 \\
\hline moto-vélo & .26 & taxi-vélo & .05 & zéro-vélo & .29 & pâté--vélo & .08 \\
\hline avion-camion & .48 . & cargo-camion & .45 & union-camion & .46 & musée-camion & .06 \\
\hline landau-bateau & .43 & bagnole-bateau & .42 & pruneau-bateau & .41 & fourmi-bateau & .07 \\
\hline cuillère-teillère & .70 & tasse-teillère & .48 & paupière--teillère & .50 & réchaud-teillère & .16 \\
\hline rouleau-couteau & .50 & carafe-couteau & .35 & bouleau-couteau & .50 & guitare-couteau & .10 \\
\hline assiette-fourchette & .51 & glacière-fourchette & .25 & sonnette-fourchette & .52 & guenille-fourchette & .24 \\
\hline chapeau-manteau & .42 & culotte-manteau & .16 & tombeau-manteau & .43 & torrent-manteau & .16 \\
\hline casquette-chaussette & .80 & babouche-chaussette & .32 & banquette-chaussette & .52 & bonhomme-chaussette & .23 \\
\hline allouette-crevette & .53 & écrevisse- crevette & .49 & jaquette-crevette & .56 & bandeau-crevette & .06 \\
\hline hareng-jument & .16 & mulet-jument & .34 & ciment--jument & .54 & ballon-jument & .07 \\
\hline étang-volcan & .17 & vallon-volcan & .62 & cadran-volcan & .44 & coffret-volcan & .07 \\
\hline chevreau-agneau & .40 & anguille-agneau & .41 & poteau-agneau & .44 & bosquet-agneau & .07 \\
\hline veston-blouson & .34 & blazer-blouson & .41 & croûton-blouson & .42 & cigale-blouson & .06 \\
\hline faisan-merlan & .34 & panthère-merlan & .28 & sultan-merlan & .36 & légume-merlan & .18 \\
\hline tricot-maillot & .34 & gilet-maillot & .34 & bistrot-maillot & .33 & farine-maillot & .07 \\
\hline crapaud-moineau & .15 & matou-moineau & .54 & rameau-moineau & .43 & jupon-moineau & .08 \\
\hline palier-escalier & .55 & échelle-escalier & .35 & bachelier-escalier & .50 & véhicule-escalier & .11 \\
\hline tricheur-menteur & .40 & vaurien-menteur & .24 & liqueur-menteur & .45 & banane menteur & .12 \\
\hline chaussure-ceinture & .63 & chandail-ceinture & .34 & chevelure-ceinture & .64 & bagage-ceinture & .22 \\
\hline$M$ & .42 & & .34 & & .43 & & .11 \\
\hline$S D$ & .15 & & .12 & & .12 & & .07 \\
\hline
\end{tabular}

(Manuscript received February 14, 1997; revision accepted for publication June 22, 1998.) 